\title{
Is routine histological examination of gall bladder specimens justifiable?
}

\author{
M I M De Zoysa ${ }^{1}$, S K L A De Silva ${ }^{1}$ and A Illeperuma ${ }^{2}$
}

(Index words: histopathology, gall bladder cancer, cost effectiveness)

\begin{abstract}
Objective To assess the safety of confining histological examination to gall bladders with radiological and macroscopic features suggestive of cancer.
\end{abstract}

Design Retrospective study.

Setting Department of Histopathology, National Hospital of Sri Lanka.

Method Analysis of all cholecystectomies performed at a tertiary care hospital during a one year period. Computerised histopathological reports and case notes were studied.

Results Four hundred and seventy seven patients had undergone cholecystectomy for symptomatic gall stones. Four of these patients were found to have gall bladder cancer. In two of them the diagnosis had been suspected on pre-operative ultrasound scan. In the other two, gall bladder cancer was suspected at the time of surgery. Gall bladder cancer was found in $0.8 \%$ of specimens and it was suspected perioperatively in all these patients.

Conclusion Our preliminary results suggest that a more selective approach to gall bladder histology may result in saving processing time and costs without adversely affecting patient safety.

\section{Introduction}

Adenocarcinoma of the gall bladder is a rare but aggressive gastrointestinal malignancy. It carries a dismal prognosis with a 5 year survival rate of less than $5 \%$ and a median survival of only 3 months, mainly due to delayed presentation [1]. Although it is associated with gall stones in $85 \%$ of cases the life time cancer risk for a patient with gall stones is only $0.5 \%$. The only recognised pre-

${ }^{1}$ Department of Surgery, Faculty of Medicine, University of Colombo, Sri Lanka. ${ }^{2}$ Department of Pathology, National Hospital, Sri Lanka.

Correspondence: MIMdeZ, e-mail <ishandz@hotmail.com>. Received 19 September and revised version accepted 6 November 2009. Competing interests: none declared. 
malignant condition is a porcelain gall bladder. Although the diagnosis of gall bladder cancer is made preoperatively in some patients, it is only suspected at the time of cholecystectomy in the majority. At present all gall bladder specimens are sent for histology regardless of the macroscopic appearance of the specimen.

In recent years there has been an increase in workload pressures on histopathologists. Increased clinical demand, more detailed analysis of specimens and minimum standards of reporting on difficult cases are the main causes, in addition to an absolute increase in specimens. The provision of adequate numbers of appropriately trained staff at all levels is critical to the provision of pathology services and maintenance of high standards [2]. Surgeons are frequently appointed to hospitals without a parallel increase in the number of histopathologists, putting further pressure on an already stretched service.

Analysis of specimens that provide no advantage to the patient, surgeon or histopathologist would seem futile. Certain tissues may not require microscopic assessment and could be selectively analysed only if a macroscopic abnormality were detected saving pathology departments' time and resources; cholecystectomy specimens may be one such tissue. In most hospitals, cholecystectomy specimens are routinely sent for histology, regardless of whether or not there is any visible macroscopic abnormality. The objective of this study was to assess whether or not it would be safe to adopt a policy of processing only those gallbladders (which on preoperative imaging or on intra-operative findings) had features suggestive of cancer, without compromising patient management and outcome.

\section{Methods}

A retrospective analysis of all cholecystectomies performed during a one year period from 1st January 2007, was conducted. Computerised histopathology records were studied. In all cases of confirmed malignancy, patients' notes were retrieved and reviewed. The results of pre-operative investigations such as liver function tests, abdominal ultrasound and computerised tomography scans and intra-operative findings of operation notes were studied in detail in these patients. All patients with gall bladder carcinoma were followed up to the present date or to their death.

\section{Results}

A total of 490 gall bladder specimens were subjected to histopathological analysis during this period. In 13 specimens, the gall bladder had been removed as part of another operation i.e. pancreatico-duodenectomy. There was no evidence of gall bladder carcinoma in any of these pancreatico-duodenectomy specimens.

Out of the 477 patients who had undergone only a cholecystectomy, chronic cholecystitis was found in 411(88.8\%) and acute cholecystitis was seen in 34 (7.1\%). One specimen showed a mucocele and another specimen was normal. Gall bladder carcinoma was detected in four patients $(0.8 \%)$. Three of these patients were females (Table 1). Two of these patients had ultrasound findings suggestive gall bladder carcinoma (Table 2). In one of these patients the diagnosis had been suspected at the time of surgery as the gall bladder contained a mass with thickening of the wall. In the other patient, a grossly thickened and densely adherent gall bladder had been removed piecemeal. In all four patients, the diagnosis was suspected perioperatively and these suspicious findings were clearly recorded on the case notes and in the histopathology request forms.

Table 1. Summary of the patients with gall bladder adenocarcinoma

\begin{tabular}{|c|c|c|c|c|c|c|}
\hline $\begin{array}{l}\text { Patient } \\
\text { no. }\end{array}$ & $\begin{array}{c}\text { Age } \\
\text { (years) }\end{array}$ & $M / F$ & $\begin{array}{l}\text { Pre-operative } \\
\text { suspicion on } \\
\text { ultrasound }\end{array}$ & $\begin{array}{l}\text { Cholecystectomy } \\
\text { type }\end{array}$ & Operative findings & Type of tumour \\
\hline 1 & 65 & F & No & Open & $\begin{array}{l}\text { Thickening with } \\
\text { multiple adhesions, } \\
\text { GB was removed } \\
\text { piecemeal }\end{array}$ & $\begin{array}{l}\text { Poorly differentiated } \\
\text { adenocarcinoma }\end{array}$ \\
\hline 2 & 56 & $\mathrm{~F}$ & Yes & Open & $\begin{array}{l}\text { Mass with thickened } \\
\text { gall bladder wall }\end{array}$ & $\begin{array}{l}\text { Well-differentiated } \\
\text { adenocarcinoma }\end{array}$ \\
\hline 3 & 52 & $\mathrm{~F}$ & No & Laparoscopic & $\begin{array}{l}\text { Mass and wall } \\
\text { thickening }\end{array}$ & $\begin{array}{l}\text { Well-differentiated } \\
\text { adenocarcinoma }\end{array}$ \\
\hline 4 & 68 & M & Yes & Open & Gross tumour & $\begin{array}{l}\text { Moderately differentiated } \\
\text { adenocarcinoma }\end{array}$ \\
\hline
\end{tabular}


Table 2. Ultrasonic and macroscopic findings in malignant and benign gallbladder specimens

\begin{tabular}{lccc}
\hline Ultrasonic and macroscopic findings & \multicolumn{2}{c}{ Histology } & Total \\
\hline Normal ultrasound and normal macroscopy & 00 & 467 & 467 \\
Normal ultrasound and abnormal macroscopy & 02 & 02 & 04 \\
Abnormal ultrasound and abnormal macroscopy & 02 & 01 & 03 \\
Abnormal ultrasound and normal macroscopy & 00 & 03 & 03 \\
Total & 04 & 473 & 477 \\
\hline
\end{tabular}

\section{Discussion}

Carcinoma of the gallbladder is reported to be the most frequent carcinoma of the extra-hepatic biliary tract. The majority are adenocarcinomas but squamous, mixed, undifferentiated types and lymphomas also occur [3]. Symptoms are often non-specific and the diagnosis often made at an advanced stage at operation for routine cholecystectomy.

Only $10-30 \%$ of gall bladder cancers (GBC) are resectable at the time of presentation. Surgical resection of the gallbladder, resection of hepatic wedges and more extensive procedures carry significant morbidity and mortality [4]. Many authors have reported that outcome in patients with stage I GBC is good after cholecystectomy alone and that radical resection should only be contemplated in stage II-IV disease. Radiotherapy has role in palliation of symptoms but chemotherapy confers no significant survival benefit [5]

In this study, we found only four cases of GBC, all of which were diagnosed pre-operatively or intra-operatively. A histological diagnosis did not alter the management or outcome of any of these patients. Furthermore, if an early GBC had been missed on macroscopic examination, it would have been successfully treated by cholecystectomy alone and no further treatment would have been necessary.

Few studies have assessed the time and cost implications of routinely sending all specimens for histology and a more considered approach has been suggested [6]. The total time taken to process one gallbladder specimen in the histopathology department of our hospital is about 15 minutes. Processing 477 specimens takes approximately 120 hours per year. The processing cost to the hospital is approximately Rs 750 per specimen. This equates to a total annual processing cost of Rs 357000 for these gall bladder specimens. Our data indicates that $467 / 477$ (97.8\%) of these gall bladders were deemed to be not suspicious on pre-operative ultrasound and macroscopic examination during surgery. If a policy of selectively processing ultrasonically or macroscopically suspicious gallbladder specimens is adopted, the cost saving to the hospital would be around Rs 350000 per year. In a country which is short of qualified histopathologists, a saving of 105 consultant hours per year could also be achieved. As such a policy is unlikely to miss any carcinomas there is no 'cost' associated with such a policy. However, the resulting benefit would be a more than 95\% saving of histopathology costs.

Although we found no cases of early GBC, there is evidence to show that early GBC is best treated by cholecystectomy alone $[7,8]$. Therefore, an unidentified early GBC would have been treated according to current standards and a histological diagnosis would not alter patient treatment or outcome. However, gall bladder histology does not necessarily have to be positive to be beneficial, as negative results may be comforting to both patient and surgeon. The argument that all specimens should be processed because of the current medico-legal climate is also not a valid justification for "routine" histopathology - if such a policy is not evidence-based. A policy could be adopted whereby the gallbladder specimen is opened at the time of surgery, the mucosa examined and any suspicious (polyps, nodules, ulcers, an indurated or thickened gallbladder wall or penetration into the liver bed) gallbladder sent for histopathological assessment.

Our study is a preliminary observation on a relatively small number of patients and larger studies should be performed before firm conclusions can be made with regard to selective or routine processing of gall bladder specimens. It will be necessary for surgeons, histopathologists and their professional colleges to agree on guidelines and protocols based on evidence from these studies before such a policy of selective histopathology of gallbladder specimens can be implemented.

\section{References}

1. Cubertafond P, Mathonnet M, Gainant A, Launois B. Radical surgery for gall bladder cancer. Results of the French Surgical Society survey. Hepatogastroenterology 1999; 46: 1567-71. 


\section{Papers}

2. Histopathology of limited or no clinical value. Report of a working group of The Royal College of Pathologists. London: Royal College of Pathologists, 2002.

3. Darmas B, Mahmud S, Abbas A, Baker AL. Is there any justification for the routine histological examination. Annals of the Royal College of Surgeons of England 2007; 89: 238-41.

4. Shirai Y, Yoshida K, Tsukada K, Muto T. Inapparent carcinoma of the gallbladder: an appraisal of a radical second operation after simple cholecystectomy. Annals of Surgery 1992; 215: 326-31.

5. Shirai Y, Yoshida K, Tsukada K, Muto T, Watanabe H.
Radical surgery for carcinoma of the gallbladder. Long term results. Annals of Surgery 1992; 216: 565-8.

6. Taylor HW, Huang JKC. 'Routine' pathological examination of the gall bladder is a futile exercise. British Journal of Surgery 1998; 85: 208.

7. Sandor J, Ihasz M, Fazekas T, Regoly-Merei J, Batorfi J. Unexpected gall bladder cancer and laparoscopic surgery. Surgical Endoscopy 1995; 9: 1207-10.

8. Yildirim E, Celen O, Gulben K, Berberoglu U. The surgical management of incidental gallbladder carcinoma. Europian Journal of Surgical Oncology 2003; 31: 45-52. 